\title{
Drafting a Reference Collection Policy
}

A reference collection policy can be useful in setting guidelines for the establishment and maintenance of an effective reference collection. It can also serve to facilitate reference service and to train new reference librarians by clarifying some reference department goals. This article indicates important elements to include in a reference collection policy. It also describes procedures followed by the Reference Collection Committee at San Diego State University in drafting its policy and includes the text of the policy currently in effect in the San Diego State University Library.

M

ANY ACADEMIC LIBRARIES have written collection policies which set criteria for depth of coverage, selection, and retirement (weeding or storage) of the library's collection. In recent years a number of academic library reference departments have recognized the need for additional guidelines in order to maintain an effective reference collection.

A reference collection policy is a useful tool for several reasons. First, it sets uniform guidelines for the collection, including subject scope, depth of coverage, and types of material to be included. Second, it provides an opportunity for coordinating the reference collection with reference service. Since the reference collection is a working collection, materials should be chosen, located, and, if necessary, duplicated, to serve the needs of reference librarians and users. Third, the reference collection policy is an effective orientation device for training new staff in making reference decisions. Finally, the policy spells out the cooperation and division

Kathleen Coleman and Pauline Dickinson are senior assistant librarians in the San Diego State University Library, San Diego, California. of labor which takes place between public service departments or, in very large institutions, between libraries, so that duplication is planned rather than unintentional.

\section{Elements to Include in a}

\section{Reference Collection Policy}

To be an effective document, the reference collection policy should include the following elements:

1. A statement of objectives, indicating the purposes of the policy.

2. Information about the subject scope of the collection, preferably within the framework of the curriculum and other needs of the academic institution as a whole.

3. The optimum size of the reference collection, if set by the department.

4. Criteria for including or excluding publications within each of the major categories of reference materials. (Are all foreign language dictionaries kept in the reference department or only those for languages taught at the institution? How comprehensive must a bibliography be in order to be considered a reference book?)

5. Responsibility for selection, as 
well as procedures followed.

6. Priorities followed in selection, such as needs of the institution, favorable reviews, recency, and language of publication.

7. Procedures for updating and weeding the reference collection.

\section{Preparation of a Reference Collection Policy for San Diego State University Library}

In June 1974 the chairperson of the Department of Reference and Instructional Services, San Diego State University Library, appointed a four-member Reference Collection Committee to coordinate the acquisition of new reference materials and to draft a reference collection policy. After performing a nearly fruitless literature search on the subject of reference collection policies, the committee decided to survey other university libraries for ideas and requested reference collection policies from sixty American and Canadian universities which, like San Diego State University, have an enrollment in excess of 20,000 students. Many libraries replied that they had no policy as yet but intended to write one in the near future. Fourteen policies of various types were received including selection policies for the entire library and reference service policies, as well as guidelines for the reference collection. The documents from University of Alberta, McGill University, University of Toronto, University of Nebraska, and University of Massachusetts were especially helpful in drafting a policy at San Diego.

The reference collection policy, now ratified by the department, is divided into seven parts: policy objectives, subject scope of the collection, collection size, types of material included, acquisition of new materials, weeding the collection, and inventory. The text follows:

\section{REFERENCE COLLECTION POLICY OF THE RESEARCH AND REFERENCE SECTION, REFERENCE AND INSTRUCTIONAL SERVICES DEPARTMENT, SAN DIEGO STATE UNIVERSITY LIBRARY}

I. Objectives of the Reference Collection Policy

A. To establish guidelines, as concrete and definite as possible, for both the subject scope of the reference collection and the materials included in it.

B. To set procedures for acquiring new materials and for weeding the collection which will ensure the development and maintenance of a complete, current, and convenient reference collection.

II. Subject Scope of the Collection

A. The Research and Reference Section provides basic and in-depth information sources in the social sciences and humanities, including education. The section also provides selective coverage of subjects of current interest not directly within these academic disciplines.

B. In addition, Research and Reference collects some other materials which have call numbers $\mathrm{Q}-\mathrm{V}$, usually within the scope of the Sciences and Engineering Library. These materials are needed to supplement service in the areas named above, and include:

1. Directories of manufacturers.

2. Test manuals in scientific fields.

3. Biographical dictionaries in scientific fields.

4. Guides to travel accommodations.

C. Research and Reference excludes the following subjects and cate- 
gories of materials, except for items very directly related to the social sciences and humanities:

1. Computer technology (included in the Sciences and Engineering Library).

2. Environment and ecology (included in the Sciences and Engineering Library).

3. Recreation materials on subjects such as bicycling, backpacking, and camping (kept in the Sciences and Engineering Library).

4. Coin and stamp catalogs.

5. Genealogy, except for works pertaining to general history studies.

6. Children's literature (kept in the Education Resource Center).

7. California, United States, and United Nations publications (kept in the Department of Government Publications), except for duplicate copies of such frequently-used sources as Statistical Abstract of the United States.

8. Pure and applied sciences (included in the Sciences and Engineering Library).

III. Size of the Reference Collection

The Research and Reference Section does not designate an absolute limit on the size of the reference collection. However, prevailing demand, changes in the curriculum, and student enrollment figures in various disciplines serve as guidelines to the relative growth rates of subject areas within the collection.

IV. Types of Materials Included in the

\section{Collection}

A. Almanacs and yearbooks. Research and Reference collects current editions of major publications for the United States and foreign countries.

B. Annual reviews. The collection includes those for major disciplines.

C. Bibliographies. Those with narrow subject scope, such as single author bibliographies, are normally kept in the stacks. More general bibliographies on broad topics are included in the reference collection. Exceptions are made for topics in great demand or of considerable current interest. Research and Reference collects the national bibliographies of major countries. For trade bibliographies, the policy is as follows:

1. The entire collection of Cumulative Book Index is kept in Research and Reference.

2. The last two years of Books in Print and its foreign equivalents are considered reference materials; earlier editions are sent to the stacks.

D. Biography. Research and Reference collects comprehensive works dealing with professional, national, and international biography, including both retrospective and current biography.

E. Concordances. Only concordances for very important authors and works are included in the reference collection; others are housed in the stacks. (Examples of works collected are concordances for Shakespeare and the Bible.)

F. Dictionaries. Research and Reference provides unilingual, bilingual, and polyglot dictionaries in major languages, as well as bilingual dictionaries for as many languages as possible, including minor ones. The section also provides specialized dictionaries (for example, covering slang, idiomatic expressions, and historical aspects of language) for major languages. Dictionaries with very limited use are not retained on reference.

G. Directories. The reference collection includes the current edition of major directories in all fields within the social sciences and the humanities. Research and Reference has city directories for San Diego only.

H. Encyclopedias. The reference collection includes all the major general encyclopedias, both single volume and multivolume. Re- 
search and Reference also collects important foreign language encyclopedias. The section will attempt to acquire revised editions of Encyclopaedia Britannica, Encyclopedia Americana, and Collier's Encyclopedia, one per year, on a rotating basis, as funds permit. In addition to the general encyclopedias, Research and Reference collects authoritative encyclopedias in specialized subject areas to support research in the social sciences and the humanities.

I. Geographical sources. Research and Reference provides authoritative atlases, maps, and gazetteers covering all areas of the world. The section does not collect topographical or geological maps, which are provided by the Sciences and Engineering Library.

J. Handbooks. Research and Reference attempts to collect current and authoritative handbooks in all fields of the social sciences and the humanities.

$\mathrm{K}$. Indexes. The section provides as many indexing and abstracting services as possible in the social sciences and the humanities, within budgetary limitations.

L. Legal materials. Reference materials-legal encyclopedias, dictionaries, digests, citators, etc.-are kept in Research and Reference. Some of the most often used case reporters, such as the Supreme Court Reporter, are kept in the reference collection, but the less frequently used ones are sent to the stacks. The Federal Reporter is shelved in the stacks rather than in Research and Reference because of its large physical volume and rapid growth rate.

M. Library catalogs. Research and Reference acquires catalogs for important collections of major libraries, emphasizing subject fields not well controlled by indexes and bibliographies.

N. Plot summaries. The section provides major, comprehensive col- lections of plot summaries. Less comprehensive works, such as Monarch Notes, are kept in Limited Loan.

O. Sacred books. Research and Reference maintains a small collection of major translations of the Bible in English, as well as English translations of sacred works significant to major world religions.

P. Style manuals. The reference collection includes all major style manuals, excluding those in scientific fields.

Q. Telephone books. Research and Reference has telephone directories for major U.S. cities and a selected group of large foreign cities. There are also directories for most California cities.

R. Theses. The section provides bibliographic information about academic theses and dissertations with Dissertation Abstracts International and other sources, including some in specific subject areas.

S. Uncataloged material. The collection includes some materials not listed in the card catalog: the Advertising Resources Center (materials related to advertising); the vertical file (pamphlets and clippings on all subjects in the social sciences and humanities); and film distributors' catalogs.

V. Acquisition of New Reference Materials

A. A four-member Reference Collection Committee has the primary responsibility for pursuing a systematic and continuous acquisition program for Research and Reference. The members are appointed by the department chairperson for a two-year term, two members being appointed each year. Two members of the committee have social science backgrounds and two have humanities backgrounds.

B. The following principles, not in order of importance, serve as guidelines for the Reference Col- 
lection Committee in deciding which titles will be ordered:

1. Judged usefulness of the publication, considering the existing collection.

2. Strengths and weaknesses of the existing collection related to current needs of the university.

3. Favorable reviews or inclusion in basic reference collection guides.

4. Reputation of the author.

5. Currency of the topic.

6. Date of publication.

7. Price of the publication.

8. Language of the publication.

C. The Reference Collection Committee searches relevant professional literature to ensure that important reference works within the subject scope of Research and Reference are in the collection. This literature searching consists primarily of:

1. Scanning review sections of these journals regularly:

Booklist

Choice

College \& Research Libraries

Journal of Academic Librarianship

Library Journal

$R Q$

RSR

Wilson Library Bulletin

2. Examining publishers' leaflets and catalogs.

3. Reviewing annual lists of reference books, such as American Reference Books Annual.

4. Checking Winchell's Guide to Reference Books and Walford's Guide to Reference Material against the library's holdings in the main card catalog. The committee will do this in order to evaluate the reference collection and determine locations of titles not in the reference collection.

D. Subject bibliographers are responsible for checking approval form slips and reviews in their respective areas for titles to be or- dered on reference funds. Subject bibliographers and teaching faculty should justify all titles requested on reference funds to ensure that the publications will be expeditiously ordered. Order cards for titles rejected by the Reference Collection Committee are returned to the recommending party with reasons for the rejection.

E. The Reference Collection Committee follows these procedures in ordering new materials:

1. The committee maintains a desiderata file of order cards received from subject bibliographers, teaching faculty, and committee members and brochures on newly published materials. The file is organized in broad subject categories. The committee meets often, once a week if possible, to review the file and make final decisions on materials to order. Each committee member reviews the file and indicates his/her recommendations. Order cards for recommended publications are sent to the Department of Bibliographic Preparation for processing.

2. The Reference Collection Committee maintains a file of photocopies of order cards submitted to the Department of Bibliographic Preparation. Like the desiderata file, this file is organized in broad subject categories. Each photocopy is stamped with the submission date to enable the committee to control orders which have been held up in Bibliographic Preparation.

3. The committee completed a count of the cards in each Library of Congress classification in the reference collection shelflist, in order to determine the subject strengths and weaknesses of the collection.

F. The budget year extends from July 1 to April 1. The reference 
fund is divided into nine monthly allocations and encumbered accordingly, as much as possible. Hopefully, this timetable will allow the committee to be both equitable and flexible in allocating the fund.

VI. Weeding the Reference Collection

A. Periodic evaluation of the works already in the reference collection is as important as acquisition of new materials, since the reference collection is a working collection of important, frequently consulted publications. Careful, regular, and systematic weeding removes older, less desirable works from the reference collection.

B. Reference librarians follow the same principles and guidelines in weeding as in acquisition of new materials. Since each discipline covered by the reference collection requires different types of materials, it is impossible to establish absolute standards to be followed in weeding. For some disciplines the reference collection should provide current material only; for others it must also provide retrospective and historical works. However, some general criteria which should be considered in weeding are:

1. Significance of the publication.

2. Age and currency of the publication.

3. Availability of later editions.

4. Physical condition of the publication.

5. Duplication of the contents in more recent works.

6. Language of the publication.

C. The reference collection is weeded in two important ways: automatic weeding of older editions of a work and periodic weeding by librarians.

1. Older volumes of many publications, particularly continuations such as directories and yearbooks, are automatically weeded from the reference collection because the designa- tion "Last Volume Reference" (LVR) appears on the official shelflist card.

2. The reference collection is weeded systematically each year. Each librarian in the Reference and Instructional Services Department is responsible for weeding one or more areas in the reference collection. Reference librarians who are subject bibliographers are responsible for their areas of specialization. If the subject bibliographer for an area is not a member of the Reference and Instructional Services Department, a reference librarian is assigned primary responsibility for weeding in the area. Reference librarians may seek the opinions of subject bibliographers and of appropriate members of the teaching faculty as needed in making weeding decisions.

D. Weeding is carried out in this way:

1. The chairperson of the Reference and Instructional Services Department is responsible for assigning subject areas to individual librarians. The chairperson will revise the weeding assignments if necessary each year.

2. Weeding activity is staggered throughout the year to minimize work-flow problems for the support staff in the Reference and Instructional Services Department and in the Department of Bibliographic Preparation. The major part of the weeding activity should ideally be carried out before June 30 of each year.

3. Each librarian, after gathering together materials to be considered for weeding, takes them to the Reference and Instructional Services office. The staff places decision slips in the publications to get the opinions of all librarians in the depart- 
ment on the proposed weeding. The librarian in charge of weeding the particular subject area notifies the subject bibliographer and/or appropriate teaching faculty members that the materials are available for review.

4. The support staff in the Reference and Instructional Services Department collects statistics of weeding and prepares a report for the department each year.

\section{Inventory of the Reference Collection} The Reference and Instructional Services Department takes a periodic inventory of the reference collection. The Reference Collection Committee is responsible for ordering replacements for missing volumes.

\section{CHECKLIST OF CRITERIA FOR ACQUISITION OF NEW MATERIALS}

1. What are the strengths and weaknesses of the existing reference collection in the subject area in question?

2. Is this topic an important one in the university curriculum?

3. Is this topic a current or popular one? Is it likely to be a passing fad or to be of continued importance?

4. Is this topic likely to be important in the future?

5. Has the work received favorable reviews?

6 . Is the work included in one or more basic reference collection guides?

7. What are the author's qualifications and reputation?

8. What is the date of publication? (In general, order works with recent publication dates if possible. Exceptions are made if the publication is a standard reference work in its subject or if the older material is of current value to the collection.)

9. How much does the publication cost? ( Titles costing more than $\$ 50$ are screened carefully. When a very expensive title is under consideration, the Reference Collection Committee consults other area libraries to determine whether or not they intend to purchase the title.)

10. Does the work duplicate material in titles already in the collection?

11. What is the language of publication? (Works in English and major foreign languages will be purchased in preference to those in minor languages.)

\section{CHECKLIST OF WEEDING CRITERIA}

1. How important is this publication?

a. Is it included in a general guide to reference works, such as Walford or Winchell?

b. Is it listed in a subject bibliography, produced either here or elsewhere?

c. How do teaching faculty members and/ or the subject bibliographers rate it?

2. How comprehensive is this publication? Are its scope and depth such that it belongs in the reference collection?

3. Is the discipline one which requires a large group of reference works? If not, is this work truly essential, or is it a marginal one which could be sent to the general collection?

4. What is the language of the publication? If it is not English, will its use be very light?

5. How frequently is this publication likely to be used in the future?

6. Is there a later edition which supersedes this publication?

7. How old is the publication? If it is an older work, is the subject matter such that current information is required by the vast majority of patrons?

8. Is the work a continuation? If so, should some or all of the older volumes be sent to the stacks?

9. Is the material in this work largely or entirely duplicated in other reference works? If so, does demand justify the duplication?

10. Are there multiple copies of this title in the reference area? If so, are they justified by heavy demand on the publication?

11. Is the book badly worn, defaced, or otherwise in poor condition? If so, can it (or should it) be replaced? 